\title{
Effect of Internal Hydrophobization on the Properties of Porous, Cementitious Materials
}

\author{
Kalina B. Grabowska ${ }^{1}$ and Marcin Koniorczyk ${ }^{2}$ \\ ${ }^{1}$ Department of Building Physics and Building Materials, Lodz University of Technology, Al. \\ Politechniki 6, Łódź, 90-924, Poland, kalina.grabowska@edu.p.lodz.pl \\ ${ }^{2}$ Department of Building Physics and Building Materials, Lodz University of Technology, Al. \\ Politechniki 6, Łódź, 90-924, Poland, marcin.koniorczyk@p.lodz.pl
}

\begin{abstract}
Water is one of the main factors affecting the durability of porous materials and it is one of the most common causes of their degradation. Physical phenomena such as freezing or salt crystallization, as well as the development of fungi and moulds, are caused by the presence of moisture. In wet material thermal conductivity coefficient increases and the heat loss begins to rise. Hydrophobization is one of the protecting methods of porous materials against water. Two different type of water-repellent agents were used for the internal hydrophobization. The first of them is an aqueous emulsion of silane: triethoxy(octyl)silane (OTES) and the second one is also an aqueous emulsion but the matrix is poly(dimethylsiloxane) (PDMS). The paper focuses on the use of organosilicon water repellents. The main purpose of this paper is to determinate the possibility of use organosilicon agents as admixtures to internal hydrophobization. We compared results obtained for two different silicon-based admixtures. We investigated influence of both water-repellents on basic characteristics such as: absorbability, capillary water absorption and mechanical properties of cement mortar as well as heat of hydration of cement paste.
\end{abstract}

Keywords: Internal Hydrophobization, Cement Mortar, Silane, Siloxane.

\section{Introduction}

In 2018, in Poland, cement sales amounted to 18 million tons (Polish Central Statistical Office, 2019). And it is growing every year. Cement-based building materials are one of the most commonly used one. But, as all we know, they are porous, which means that their resistance to water is insufficient. Water is one of the main factors affecting the durability of porous materials and it is one of the most common causes of their degradation. Physical phenomena such as freezing or salt crystallization, as well as the development of fungi and moulds, are caused by the presence of moisture. In wet material thermal conductivity coefficient increases and the heat loss begins to rise. Not to mention aesthetic features (e.g. stains) and deterioration of the microclimate. The appropriate design and composition of building material may already be a part of protection against water. The hydrophobization process might complement to these actions. Hydrophobization can be carried out in two ways from the technological point of view. The material may become hydrophobic by applying water-repellent coatings on the surface or by using suitable admixtures as one of the components. Internal hydrophobization carried out with the hydrophobic admixtures causes, contrary to surface treatment, the hydrophobization of the surface and internal surface (Barnat-Hunek, 2016).

There are very limited number of regular studies or they are insufficient in determining the effectiveness of internal hydrophobization of cement-based building materials with 
organosilicon compounds. In this paper we investigate the influence of two different siliconbased admixtures on fundamental properties of cement mortar/paste. The addition of hydrophobic admixtures to the batch water was intended to create a hydrophobic material in its whole volume.

\section{Hydrophobizing Agents}

Considering the chemical nature of porous building materials, it can be seen, that silicon compounds (silicon dioxide, silicates, aluminosilicates etc.) are part of natural and manufactured building materials. Therefore, organosilicon compounds have found practical use in the hydrophobization of building objects. They are mainly based on and silicon-oxygen (Si$\mathrm{O}$ ) and silicon-carbon ( $\mathrm{Si}-\mathrm{C})$ bonds. The basic structure of organosilicon compounds is a polysiloxane chain (O-Si-O-Si-O) and the type of substituents affects the diversity of spatial arrangements that can be created from the basic chains (Barnat-Hunek, 2016).

Science the 1950's silicon-based compounds have been used in industrial applications. Hydrophobic agents based on organosilicon compounds are the youngest, and the most promising, group of hydrophobic agents for internal treatment. The main groups of these compounds are alkylsilanes, arylsilanes, halosilanes, silanols, siloxanes, silylamines and silyl esters. Among all different kind of hydrophobic products developed for the building industry, silicone resins, silanes, oligomeric and polymeric siloxanes have proved to perform best in surface hydrophobization. Until recently stearates and oleates were used as waterproofing

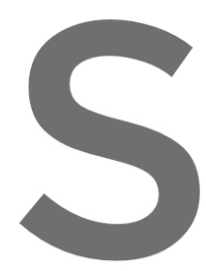
admixtures. Effective surface use them as admixtures admixtures are the most Grabowska et al., 2019; 2.1 Triethoxy(octyl)sirame
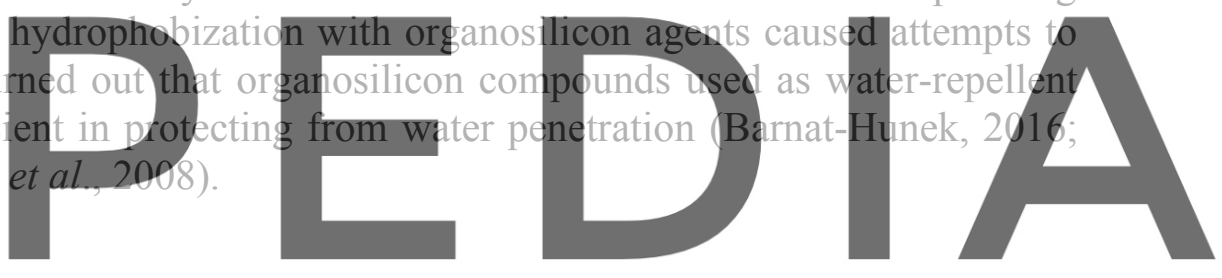

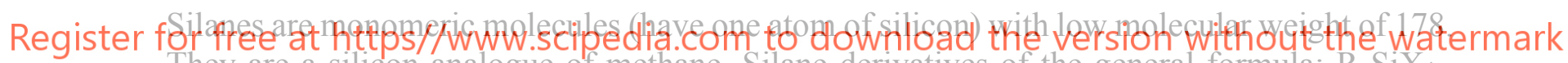
They are a silicon analogue of methane. Silane derivatives of the general formula: $\mathrm{R}_{n} \mathrm{SiX}_{4-n}$ have the most important practical significance ( $\mathrm{R}$ can be a hydrogen atom, an alkyl or aryl group, X can be a halogen atom or an alkoxy group). Longer alkyl chain-length provides desired water resistance of the modified material and steric protection to the silicon-oxygen bond. Initially silanes undergo hydrolysis and polycondensation reactions. Subsequently they crosslink under elimination of alcohol and as a result of which polymers, with polysiloxane chain, are formed. (Ciabach, 2001; Roos et al., 2008). Triethoxy(octyl)silane is an alkyl alkoxy silane with three ethoxy groups and one octyl group in its structure (Fig 1).<smiles>CCC[Si](OCC)(OCC)OCC</smiles>

Figure 1. Structure of triethoxy(octyl)silane. 


\subsection{Poly(dimethylsiloxane)}

Siloxanes are oligomeric molecules with a molecular weight about 400-600. The basic structure of siloxanes is a polysiloxane chain $(\mathrm{O}-\mathrm{Si}-\mathrm{O}-\mathrm{Si}-\mathrm{O})$. Polysiloxanes are versatile materials. They have an excellent chemical, physical, and electrical properties. Poly(dimethylsiloxane) (PDMS) is an important example and the most common polysiloxane of this class of polymers. The chains of polysiloxanes consist alternately connected silicon and oxygen atoms. Inorganic chain and the presence of strong bonds ( $\mathrm{Si}-\mathrm{O}$ and $\mathrm{Si}-\mathrm{C}$ ) provide significant thermal and oxidative resistance as well as resistance to UV radiation of polysiloxanes. Despite of the polar character of siloxane bonds ( $\mathrm{Si}-\mathrm{O}$ bonds have ionic character in 50\%) organosilicon compounds show similarity to paraffins in terms of low critical surface tension. Siloxanes have very low surface energy and exceptional hydrophobicity. PDMS chains are arranged in helixes and present of the methyl groups $\left(-\mathrm{CH}_{3}\right)$ give hydrophobic character of modified materials. Weak intermolecular interactions, characterizing PDMS, provide a significant gas diffusion coefficient. Organosilicon compounds, compared to other polymers, are characterized by very high oxygen, nitrogen and water vapor permeability (Chruściel et al., 2008, Cypryk et al.,2007; Grabowska et al., 2019;).
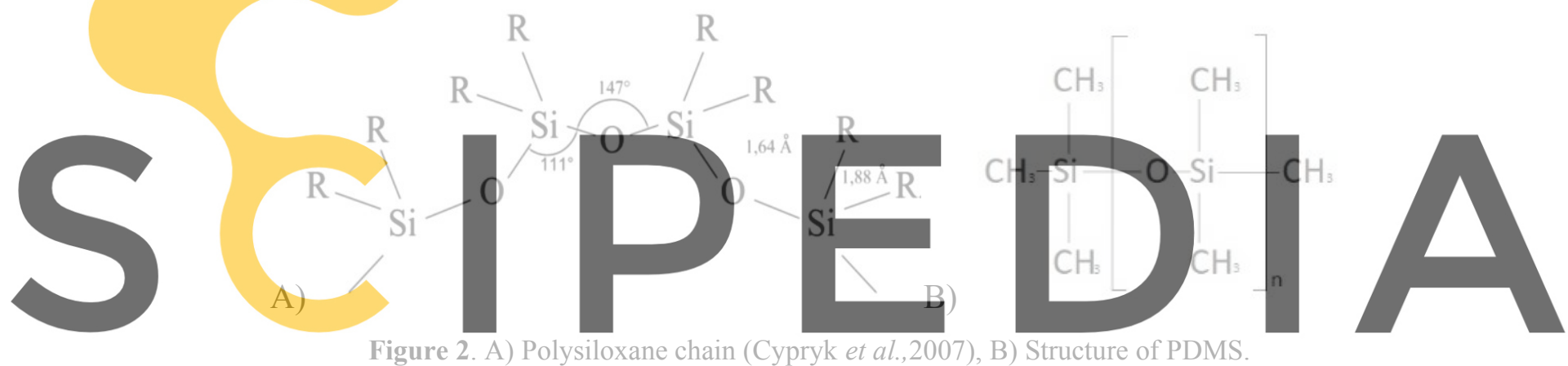

Register for free at https//www.scipedia.com to download the version without the watermark 3 Materials

The Ordinary Portiand Cement $42.5 \mathrm{R}$ was used. Table 1 shows composition of investigated cement mortars. They were prepared according to Polish standard PN-EN 196-1 with a watercement ratio (w/c) equal to 0.5 . Prismatic samples of mortar, with dimensions $160 \times 40 \times 40 \mathrm{~mm}$, were prepared for mechanical, absorbability and capillary water absorption tests. Isothermal calorimeter was used to determine the influence of organosilicon admixtures on the heat of hydration of cement paste.

Two different type of water-repellent agents were used for the internal hydrophobization. The first of them is an aqueous emulsion of silane: triethoxy(octyl)silane (OTES). The second admixture is also an aqueous emulsion but the matrix is poly(dimethylsiloxane) (PDMS). The amount of the hydrophobic admixture in cement mortar or paste was $0 \%, 1 \%, 2 \%$ or $3 \%$ (refer to cement mass). They were added to the batched water. Both admixtures are recommended for volume hydrophobization. 
Table 1. Composition of cement mortar.

\begin{tabular}{|c|c|c|c|}
\hline & \multicolumn{3}{|c|}{ Water repellent agent } \\
\hline & \multicolumn{3}{|c|}{ OTES/ PDMS } \\
\hline & $1 \%$ & $2 \%$ & $3 \%$ \\
\hline $\mathbf{W} / \mathbf{C}$ & \multicolumn{3}{|c|}{0.5} \\
\hline Cement [g] & \multicolumn{3}{|c|}{450} \\
\hline Sand $[g]$ & \multicolumn{3}{|c|}{1350} \\
\hline Water [g] & \multicolumn{3}{|c|}{225} \\
\hline Admixture [g] & 4.5 & 9.0 & 13.5 \\
\hline
\end{tabular}

\section{Results}

\subsection{Mechanical Test}

Table 2 shows the results of mechanical test received after 1, 2, 7 and 28 days of curing for hydrophobized cement mortars. Results shown in Table 2 represent the average value taken over six samples. The compressive strength test was carried out on halved, prismatic samples left after flexural strength test. Results of each test of cement mortar admixed PDMS show substantial decrease poly(dimethylsiloxane) almost a factor of two. compressive strength af mechanical strength. After 28
(PDMS) based admixture decreases
The addition of $1 \%$ silane admixture do
of silane after $1,2,7$ and 28 days and $\mathrm{f}$. 7 days of curing. Noticeable
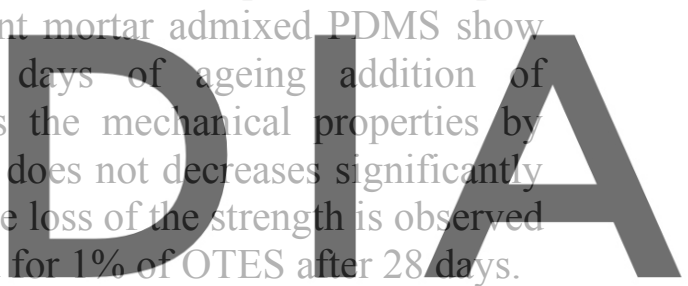

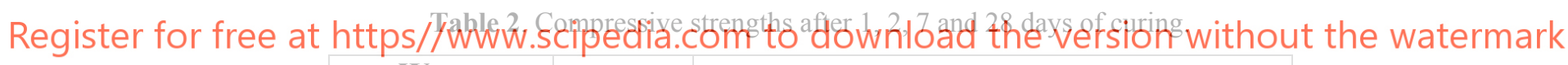

\begin{tabular}{|c|c|c|c|c|c|}
\hline \multirow{2}{*}{$\begin{array}{c}\text { Water } \\
\text { repellent } \\
\text { agent }\end{array}$} & Amount & \multicolumn{4}{|c|}{ Compressive strength [MPa] } \\
\cline { 3 - 6 } Reference & $0 \%$ & 14.40 & 23.04 & 31.16 & 45.25 \\
\hline \multirow{3}{*}{ OTES } & $1 \%$ & 13.17 & 22.34 & 32.71 & 38.35 \\
\cline { 2 - 6 } & $2 \%$ & 8.27 & 18.22 & 28.72 & 38.19 \\
\cline { 2 - 6 } & $3 \%$ & 7.05 & 17.18 & 27.59 & 36.36 \\
\hline \multirow{3}{*}{ PDMS } & $1 \%$ & 5.03 & 8.76 & 10.47 & 25.84 \\
\hline & $2 \%$ & 3.83 & 8.31 & 9.02 & 23.53 \\
\cline { 2 - 6 } & $3 \%$ & 3.65 & 9.07 & 11.91 & 22.16 \\
\hline
\end{tabular}

\subsection{Absorbability}

Absorbability of hydrophobized cement mortar is shown in Table 3. The test was carried out on three specimens for each composition. After 28 days of curing prismatic samples were dried and, after that, progressively flooded with water. Subsequently mortar samples were weighed 
every 24 hours until constant weight was received. The addition of silane admixture and $2 \%$ of PDMS admixture decrease significantly absorbability. Lower values was observed for silane.

Table 3. Results of absorbabilty test of hydrophobized cement mortar.

\begin{tabular}{|c|c|c|}
\hline Water repellent agent & Amount & Absorbability \\
\hline Reference & $0 \%$ & $7.6 \%$ \\
\hline \multirow{3}{*}{ OTES } & $1 \%$ & $3.9 \%$ \\
\cline { 2 - 3 } & $2 \%$ & $2.3 \%$ \\
\cline { 2 - 3 } & $3 \%$ & $2.2 \%$ \\
\hline \multirow{3}{*}{ PDMS } & $1 \%$ & $6.3 \%$ \\
\cline { 2 - 3 } & $2 \%$ & $3.7 \%$ \\
\hline & $3 \%$ & $6.5 \%$ \\
\hline
\end{tabular}

\subsection{Capillary Water Absorption Test}

One of the most common tests to show hydrophobic effect is capillary water absorption test. Table 4 presents the results taken over three halved, prismatic samples (six in total). Test was carried out according to PN-EN 1015-18. After 28 days of curing mortar samples were dried at $80^{\circ} \mathrm{C}$. Thereafter sealing material was applied on the side surfaces of mortar specimens ( $40 \mathrm{x}$

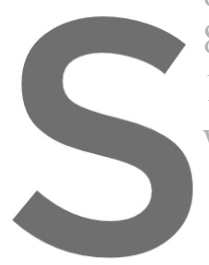
$80 \mathrm{~mm})$. Mortar prisms

10 min, 30 min, 60 min water absorption coefficin Table 4. Results of capillary water absor]
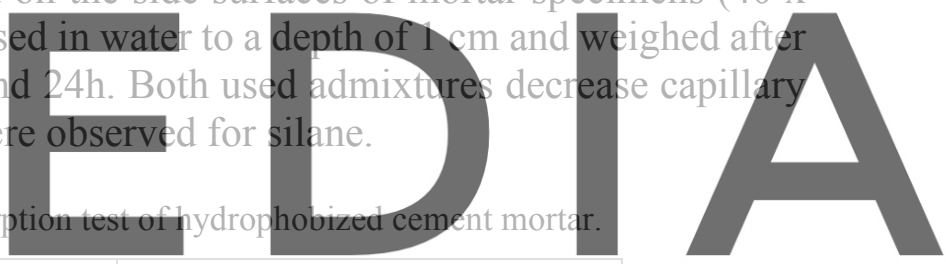

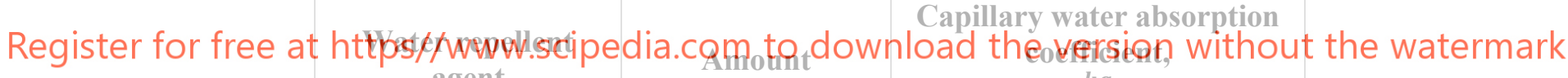
agent

$$
\frac{\mathrm{kg}}{\mathrm{m}^{2} * \min ^{0,5}}
$$

\begin{tabular}{|c|c|c|}
\hline \multirow{2}{*}{ Reference } & $0 \%$ & 0.206 \\
\hline \multirow{3}{*}{ OTES } & $1 \%$ & 0.042 \\
\cline { 2 - 3 } & $2 \%$ & 0.023 \\
\hline \multirow{3}{*}{ PDMS } & $3 \%$ & 0.020 \\
\hline \multirow{2}{*}{} & $1 \%$ & 0.115 \\
\cline { 2 - 3 } & $2 \%$ & 0.106 \\
\hline
\end{tabular}




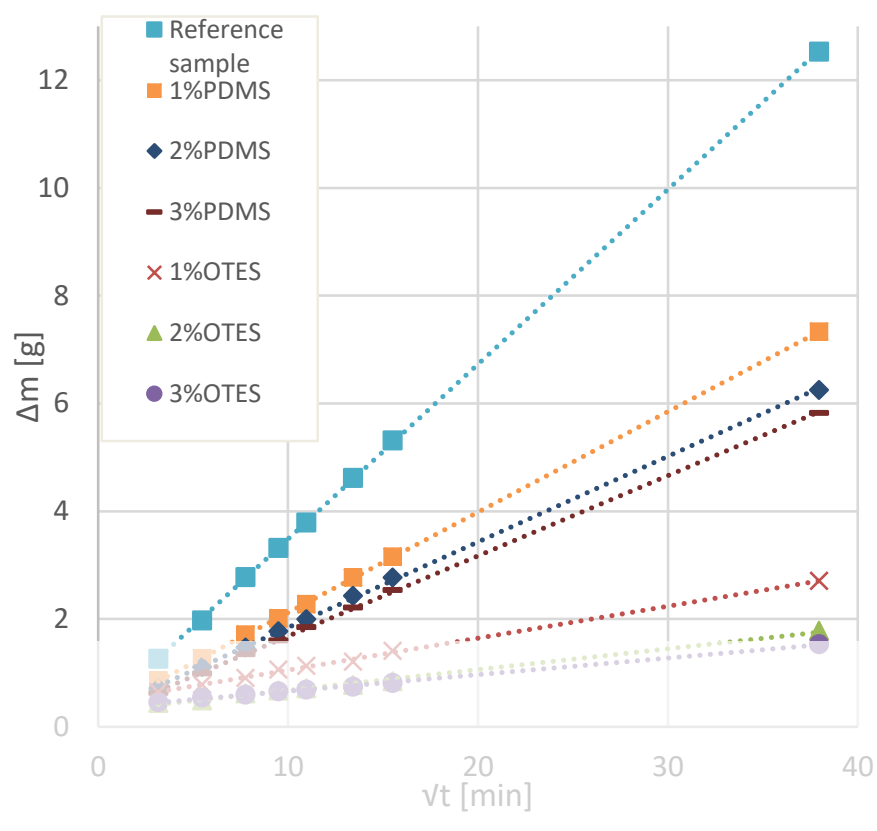

Figure 3. Mass changes of cement mortar samples during capillary water absorption test.

\subsection{Heat of Hydration}

The heat of hydration of chas ratio was 0.5 and the $\mathbf{P}$ calorimeter TAM Air, a sample. Two samples ver
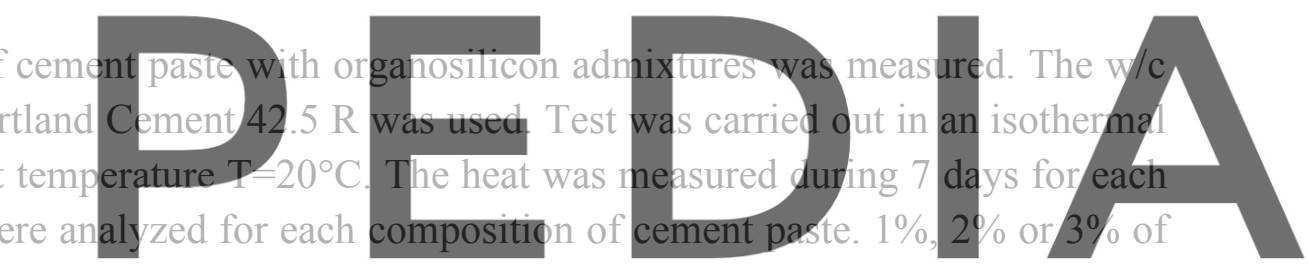

organosilicon admixture was added per cement mass. The heat of hydration after 41 hours is

Register folofree atalattês//www.scipedia.com to download the version without the watermark

Table 5. Influence of organosilicon admixtures on heat of hydration.

\begin{tabular}{|c|c|c|}
\hline Water repellent agent & $\begin{array}{c}\text { Amount of } \\
\text { admixture }\end{array}$ & $\begin{array}{c}\text { Average hydration } \\
\text { heat after 41 h [J/g] }\end{array}$ \\
\hline \multirow{2}{*}{ Reference } & $0 \%$ & 217.25 \\
\hline \multirow{2}{*}{ OTES } & $1 \%$ & 180.00 \\
\cline { 2 - 3 } & $\mathbf{1 \%}$ & 157.78 \\
\hline \multirow{2}{*}{ PDMS } & $3 \%$ & 149.12 \\
\cline { 2 - 3 } & $1 \%$ & 187.10 \\
\cline { 2 - 3 } & $2 \%$ & 199.70 \\
\hline
\end{tabular}




\section{Discussion}

The presented test results unequivocally demonstrate the interaction between used admixtures and the cement matrix. Both admixtures gave a visible hydrophobic effect. The addition of admixture based on PDMS successfully reduces capillary water absorption. For reference sample capillary water absorption coefficient was $0.21 \mathrm{~kg} /\left(\mathrm{m}^{2 *} \min ^{0.5}\right)$ and 0.098 $\mathrm{kg} /\left(\mathrm{m}^{2 *} \min ^{0.5}\right)$ for cement mortar containing 3\% of PDMS admixture. Absorbability of hydrophobized cement mortar decrease to $3.7 \%$ from $7.6 \%$. As it was shown in Table 5 poly(dimethylsiloxane) also interacts with Portland cement. The heat of hydration of Portland cement decrease from $217,25 \mathrm{~J} / \mathrm{g}$ to $182,05 \mathrm{~J} / \mathrm{g}$. Even better hydrophobic results in reducing capillary water absorption and absorbability were obtained for the second admixture based on triethoxy(octyl)silane. This water-repellent agent decreases capillary water absorption by almost $90 \%$ (from $0.21 \mathrm{~kg} /\left(\mathrm{m}^{2 *} \mathrm{~min}^{0.5}\right.$ ) to $0.02 \mathrm{~kg} /\left(\mathrm{m}^{2 *} \mathrm{~min}^{0.5}\right)$ ) and reduce absorbability by $70 \%$ (from $7.6 \%$ to $2.2 \%$ ) at the maximum amount of admixture. Also, in case of silane admixtures heat of hydration was reduced. The lowest value was obtained for 3\% of OTES (149.12 J/g). Unfortunately, both admixtures decrease compressive strength of cement mortar. The largest decreases in compressive strength were observed for the content of $3 \%$ of silicon-based admixtures. PDMS admixture reduce mechanical strength of cement mortar by an average of $50 \%$ and OTES one only by $15 \%$

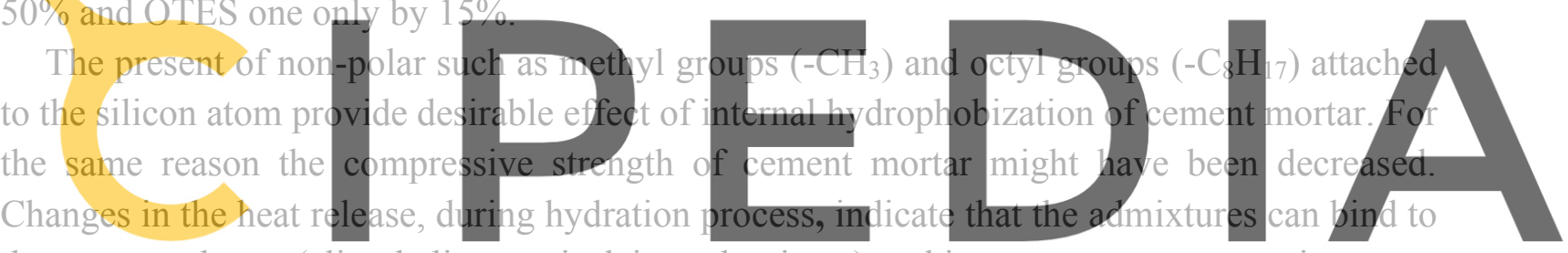

the cement phases (alite, belite or tricalcium aluminate) making water-cement reaction more

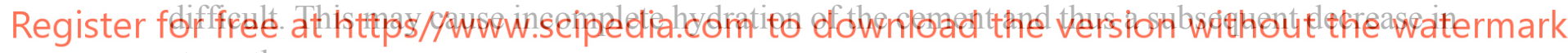
strength.

\section{Conclusions}

From the obtained results obtained the following conclusions can be drawn:

- Internal hydrophobization by using organosilicon admixtures is possible, but it has its own limitations. The hydrophobic effect depends on type of used organosilicon compound.

- Both admixtures were recommended for internal hydrophobization of cementitious materials by the producers. But treatment with triethoxy(octyl)silane gives better hydrophobic effect than poly(dimethylsiloxane) by reducing the capillary water coefficient by $90 \%$.

- Both admixtures decrease in compressive strength, but OTES based admixture reduce it by $15 \%$ and PDMS one by up to $50 \%$. 
As a conclusion, it can be said that triethoxy(octyl)silane is an efficient water-repellent agent for cementitious materials. However, the first results are very promising, but this issue still requires more studies. Especially when it comes to mechanical properties.

\section{ORCID}

Kalina Grabowska: http://orcid.org/ 0000-0003-1232-8399

Marcin Koniorczyk: http://orcid.org/ 0000-0002-6887-4324

\section{References}

Barnat-Hunek, D. (2016). Swobodna energia powierzchniowa jako czynnik ksztattujacy skuteczność hydrofobizacji w ochronie kostrukcji budowlanych (in Polish). Wydawnictwo Politechniki Lubelskiej, Lublin, Poland.

Chruściel, J., Leśniak, E. and Fejdyś, M. (2008). Karbofunkcyjne silany i polisiloksany. Cz. II. Otrzymywanie i zastosowania karbofunkcyjnych polisiloksanów (in Polish). Polimery, 53 (11-12), 817-828.

Ciabach, J. (2001). Właściwości żywic sztucznych stosowanych w konserwacji zabytków (in Polish). Wydawnictwo Uniwersytetu Mikołaja Kopernika, Toruń, Poland.

Cypryk, M., Delczyk, B., Pospiech, P. and Strzelec, K. (2007). Modyfikacje polimerów siloskanowych (in Polish). Polimery, 52 (7-8), 496-502.

Grabowska, K. and Koniorczyk, M. (2019). The effect of hydrophobic treatment by organosilicon admixtures of cement mortar. Cement Wapno Beton, 4, 320-329.

Polish Central Statistical Office ("GUS") (2019). Outlays and results in industry in 2018. Statistical information.

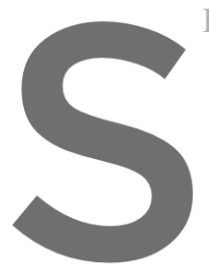

Roos, M., König, F., Stad for Modern Building Materials Hydrophobe
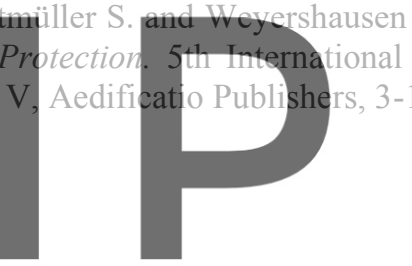
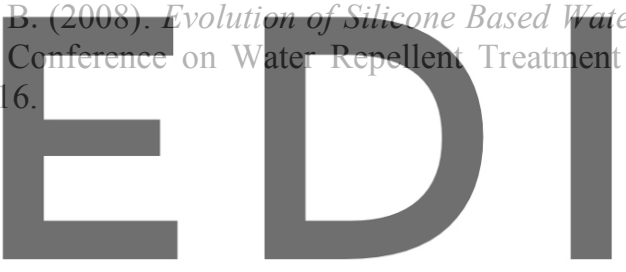

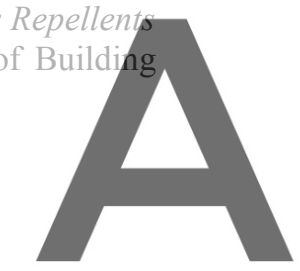

Register for free at https//www.scipedia.com to download the version without the watermark 